\title{
INTEGRATED STUDENT GROUP PRESENTATION IN TEACHING DEVELOPMENTAL MATHEMATICS COURSES
}

\author{
Qingxia Li, PhD \\ Assistant Professor in Mathematics \\ Fisk University, Nashville, Tennessee, USA
}

\begin{abstract}
The purpose of this study is to examine whether there is a difference in students' understanding of the core concepts in Pre-calculus after integrating student group presentations into teaching versus the teacher-led traditional classroom setting. The results of the analysis indicated that student group presentations do increase student retention and success rate, the number of students obtaining an $\mathrm{A}$, and the final exam average. The model of integrating group presentation in teaching developmental mathematics courses should be adapted.
\end{abstract}

Keywords: Pre-calculus, group presentation, student retention rate, student success rate, core concepts

\section{Introduction}

Employers are in high demand of graduates with excellent communication skills. Therefore, a student's in-class presentation becomes an important element in training students to deliver information of their learning (Alshare, 2004). Hempel etl did a study in didactical ultrasound courses and found out that only a limited amount of information can be processed at a time and $12 \%$ of knowledge can be retained after 2 weeks. Presentations of short duration can increase the retained knowledge rate. Therefore, classroom-based presentations in teaching should be adapted (Hempel, 2014).

Fan and YEO (Fan, 2007) in Singapore integrated oral presentations into mathematics teaching and learning. Their study showed that both teachers and students initially encountered difficulties and challenges in applying this new teaching strategy in the classrooms. However, both teachers and students believe that using oral presentations in class can be effective in teaching and learning after gaining experiences. They concluded from the results that it is meaningful to integrate oral presentations into 
teaching and learning given necessary guidance and training for both students and instructors.

One can only learn when one can teach. When students talk about mathematics, it is usually not easy to understand what they really mean. Even if their reasoning is correct, it may not appear to be sound when they try to convert their thoughts into words. So it is very important to re-voice their learning through in-class presentation. Re-voicing can help students to understand math content or core concepts and increase students' critical thinking (Chapin, 2003).

Pre-calculus is a unified course with the same content as College Algebra and Trigonometry. It is one of the prerequisites for Calculus I which is required by most of Science, Technology, Engineering and Mathematics (STEM) majors. In the first half of this course, college algebra is the main focus and the core concepts include graphing algebraic, logarithmic, and exponential functions, and solving the algebraic, logarithm, and exponential equations (and inequalities). The second half of this course will mainly cover the basic trigonometry properties which include graphing and evaluating trigonometric functions, solving trigonometric equations, and solving three variable linear system with matrix. When students have learned trigonometry during the second of half of the semester, they tend to forget the algebra (from the beginning). Furthermore, students in Pre-Calculus had great difficulty in understanding the core concepts of this course, specifically the definition of a function, trigonometric functions, and algebraic expressions of fractions. Lacking this basic knowledge, students encountered difficulties in solving quadratic equations and linear inequalities, and graphing trigonometric and rational functions. Furthermore, they are also confused when learning inverse functions, exponential functions, and trigonometric formulas, which are core topics in this course.

The main purpose of this study is to get students to become interested in the world of mathematics and other related STEM courses. Group presentation will provide students an opportunity to think logically and creatively when solving mathematics problems. A mathematically-based problem solving approach to life will likely increase the probability that these students choose STEM careers. The main objectives of this project are to help students to be prepared for upper level mathematics courses that their majors might require and to increase their presentation skills and critical thinking.

\section{Design}

Rationale: This project is conducted at an open enrollment (historically black) university in the Midwest of the United States. The student body at this institution is extremely diverse, which includes a large 
proportion of underrepresented minorities, non-traditional students, and academically unprepared students. The investigator of this project noticed that most students who struggled in Pre-calculus had difficulties in understanding the core concepts and would be unlikely to participate in the class discussion. After the pilot study in academic year 2010-2011 and one on one discussion with these students, the investigator found out that students felt embarrassed to participate in the discussion without knowing the basic concepts. In addition, students would get lost easily when they watched the online tutorial videos or reviewed the notes by themselves. These factors were significant obstacles for them to participate in the class activities. In order to spur students' interest in mathematics and build a solid background to pass Pre-calculus, the investigator implemented student group presentation to help students understand the core concepts.

Design: A pilot study was conducted during the academic year 20102011. Students showed great interest in group presentations in Pre-Calculus. The study will use a quasi-experimental non-equivalent control group design. The Experimental group will use the applied teaching method-student group presentation while the Baseline group will apply the traditional teacher directed classroom setting. The group differences will serve as the independent variables in the study. Dependent variable measures will focus on the quantity and quality of skills and knowledge. The Baseline group consists of the data such as the retention rate and grade distribution collected from the academic year 2011-2012. The Experimental group will be the data collected from the academic year 2012-2013. By comparing the data collected from these two groups, students from Experimental group are expected to show an increase in retention rate and passing rate.

Participants: Participants of this project included approximately 75 bstudents enrolled in Pre-calculus at a (historically black) university in the Midwest of United States. The institution is an open-enrollment institution with a large portion of underrepresented, nontraditional, and unprepared students.

Student Resources: Two online resources were available for student viewing and used as supplementary materials for their presentations. One is videos of my own presentations on core concepts and applications of mathematics in real life. I introduced an expanded emphasis on applications to promote an appreciation for mathematics in STEM majors. For instance, one example I used in this course is traveling waves (physics): If we snap photographs of the string at several instants, it appears that the waves in the string "travel" to the right. The velocity of the wave is the rate at which it moves to the right. If the wave has the velocity $\mathrm{v}$, the graph of the shifted wave at time $t$ is $y(x, t)=A \sin k(x-v t)$, which is a sine function. The graph of sine function is a very important technique in Pre-calculus. Another 
example is $\mathrm{pH}$ scale and hydrogen ion concentration (chemistry): Chemists defined a convenient expression of $\mathrm{pH}$ and hydrogen ion concentration as

$$
\mathrm{pH}=-\log \left[\mathrm{H}^{+}\right] \text {, }
$$

where $\left[\mathrm{H}^{+}\right]$is the concentration of hydrogen ions measured in moles per liter. It is clear for students to use a calculator to find the corresponding $\mathrm{pH}$ given the hydrogen ion concentration. But how could students find corresponding $\left[\mathrm{H}^{+}\right]$given $\mathrm{pH}$ ? This is an application of solving logarithmic functions. Students can solve the logarithmic functions by rewriting the equation in the form of exponential function: $\left[\mathrm{H}^{+}\right]=10^{-\mathrm{pH}}$ and they can find solutions by substituting the numbers into the formulas.

The second resource is shared online videos from Louisiana State University. With permission of Louisiana State University Math Coordinator Mrs. Phobe Rouse, I shared on-line lecture videos (https://www.math.lsu.edu/courses/videos) to support student preparation for their group presentations in this course. In these online videos, examples of solving questions were a main focus.

Guideline of Group Presentation: Students were randomly divided in groups and each group was in charge of one algebra core concept and one trigonometry core concept. During student presentations, students are strongly encouraged to ask questions and participate in the discussions. At the end of each presentation, the instructor points out the strength and areas of improvement so that students can gain immediate feedback. The presentation score is counted as $10 \%$ of their course grade. The guidelines of presentations:

1. Each presentation should include three parts: Introduction, Applications and a brief Summary.

i) Introduction: The introduction is mainly about student understanding of the core concepts for the assigned topics. Students are encouraged to present in both a conceptual and graphical view.

ii) Applications: Then students need to find real-life applications or examples in their disciplines. These examples could not be the examples directly from our textbook or my class notes. Students are also required to write up some questions for their classmates to practice for their final exams.

iii) Summary: The summary included a brief review of the core concept and the key ideas in applying these concepts to solve problems.

2. Each student in the group has to present part of their assigned topics. Each presentation consists of 15-16 minutes of lecturing, followed by a 4-5 minute question-and-answer period. Presenters should prepare 
several questions to involve the whole class. The questions were intended to include all levels from straightforward to challenging.

3. After each presentation, a quiz is given to the rest of the class except for the presenters. The average score of the quiz will be added to the presentation score of that group. The final exam will include questions to check their understandings of these core concepts and formulas.

\section{Results}

The data attached below was collected from the Pre-calculus classes from Fall 2010 to Spring 2013. In Fall 2012, 21 students were enrolled in this course (note: three students never showed up to the class and were dropped accordingly). For the remaining 18 students, 16 students received a letter grade and two students withdrew as the semester progressed. Among the students who received letter grades, eight of them scored A's, three B's, three C's, and two failed the course. The retention rate of 2012-2013 was $16 / 18=88.89 \%$ and the passing rate was $14 / 16=87.5 \%$.

In the academic year 2011-2012, 27 students were enrolled in this course at the start of the semester. Due to financial and academic reasons eight students left the class in the middle of the semester. 18 students stayed and received a letter grade and one student decided to audit the course. Among the students who obtained a final course grade, six students scored A's, two B's, seven C's, and three failed the course. The retention rate of 2011-2012 was 19/27 $=70.37 \%$ and the passing rate was $15 / 18=83.33 \%$.

For the academic year of 2010-2011, there were 28 students who originally registered the course, and 9 of them withdrew the course in the middle of this semester. The final grade distribution of this course: seven scored A's, four B's, six C's, one D, and one student failed the course. Hence, the retention rate of $2010-2011$ was $19 / 28=67.86 \%$ and the passing rate was $17 / 19=89.47 \%$. 
FIGURE 1: Grade Distribution of Academic Year 2010-2011, 2011-2012 and 2012-2013.

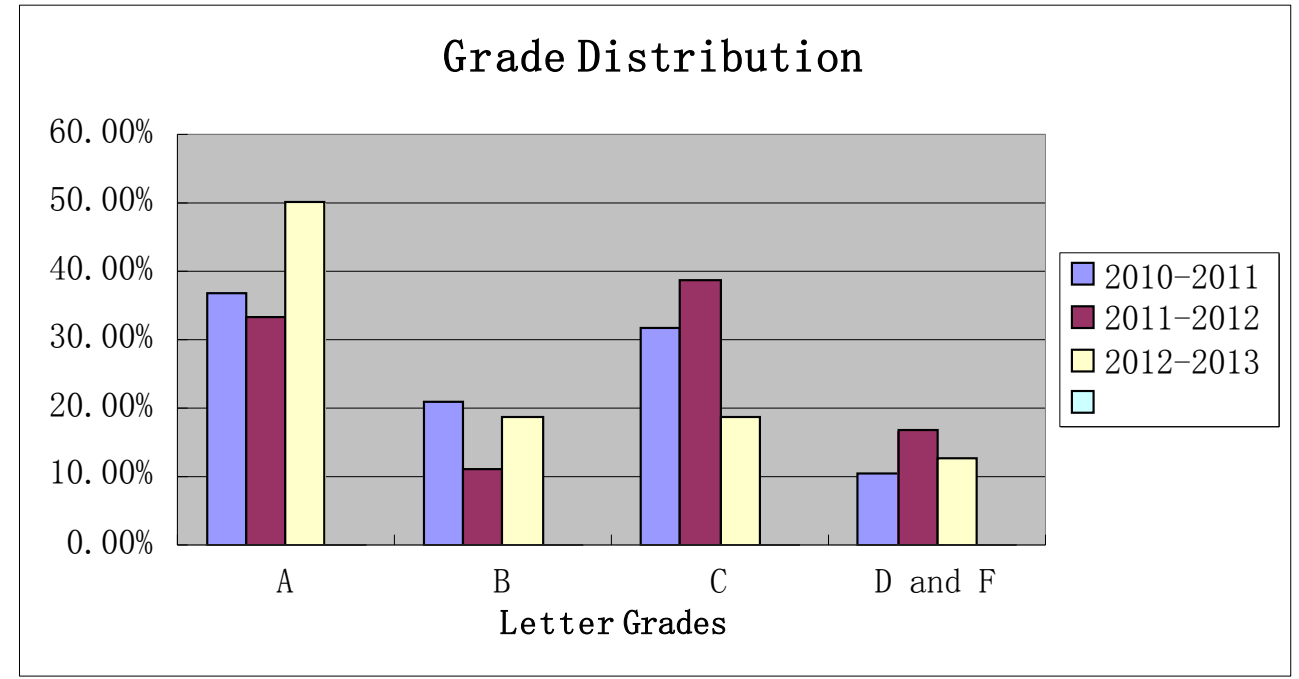

FIGURE 2: Retention Rate and Passing Rate of Academic Year 2010-2011, 2011-2012 and 2012-2013.

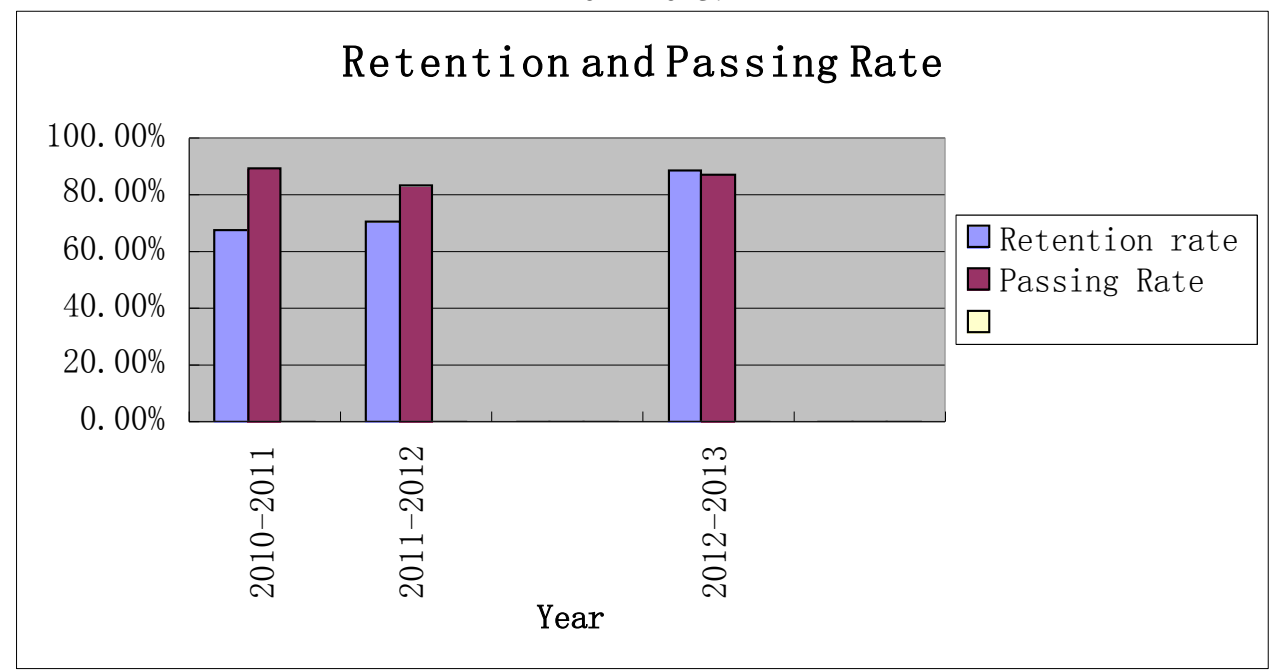


FIGURE 3: Final Exam Grade vs. Group

\section{Final Exam Grade vs. Group Presentation Score}

Final Exam Grade $=-1.91+0.8823$ Group Presentation Score

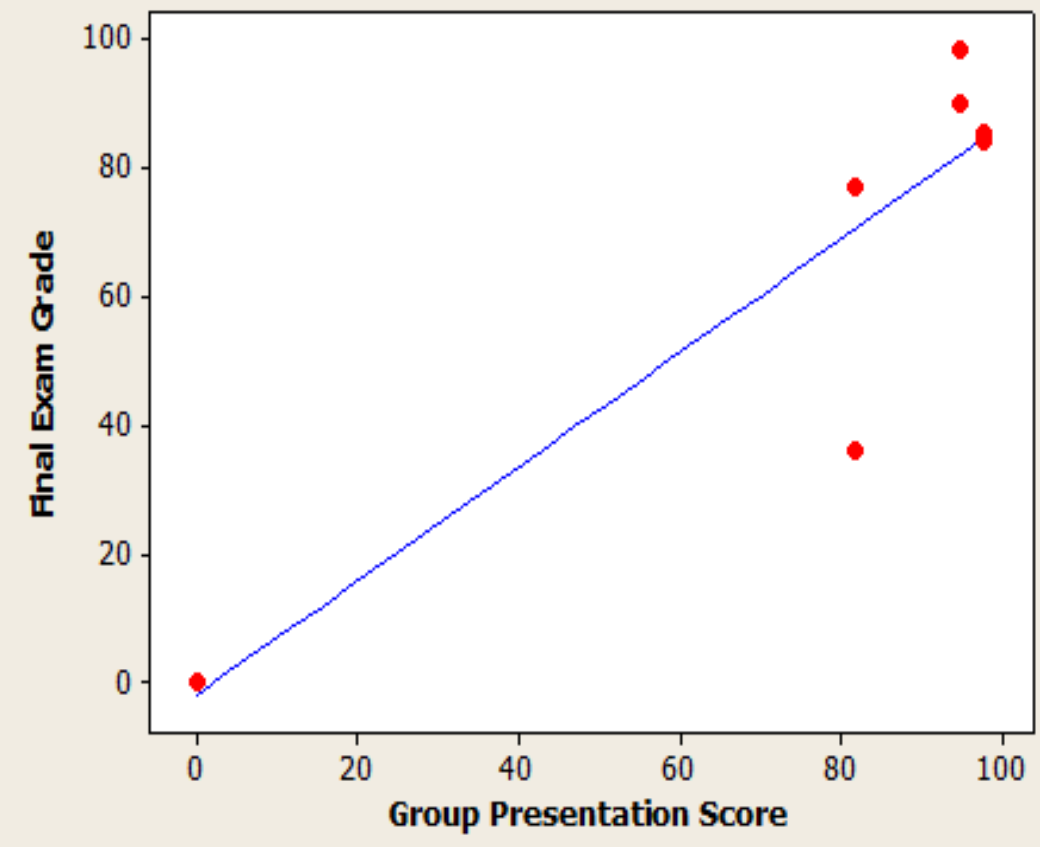

\begin{tabular}{|lr|}
\hline S & 16.1311 \\
R-Sq & $86.5 \%$ \\
R-Sq(adj) & $84.3 \%$ \\
\hline
\end{tabular}

FIGURE 4: Average of final examPresentation Score in 2011-2012 and 2012-2013.

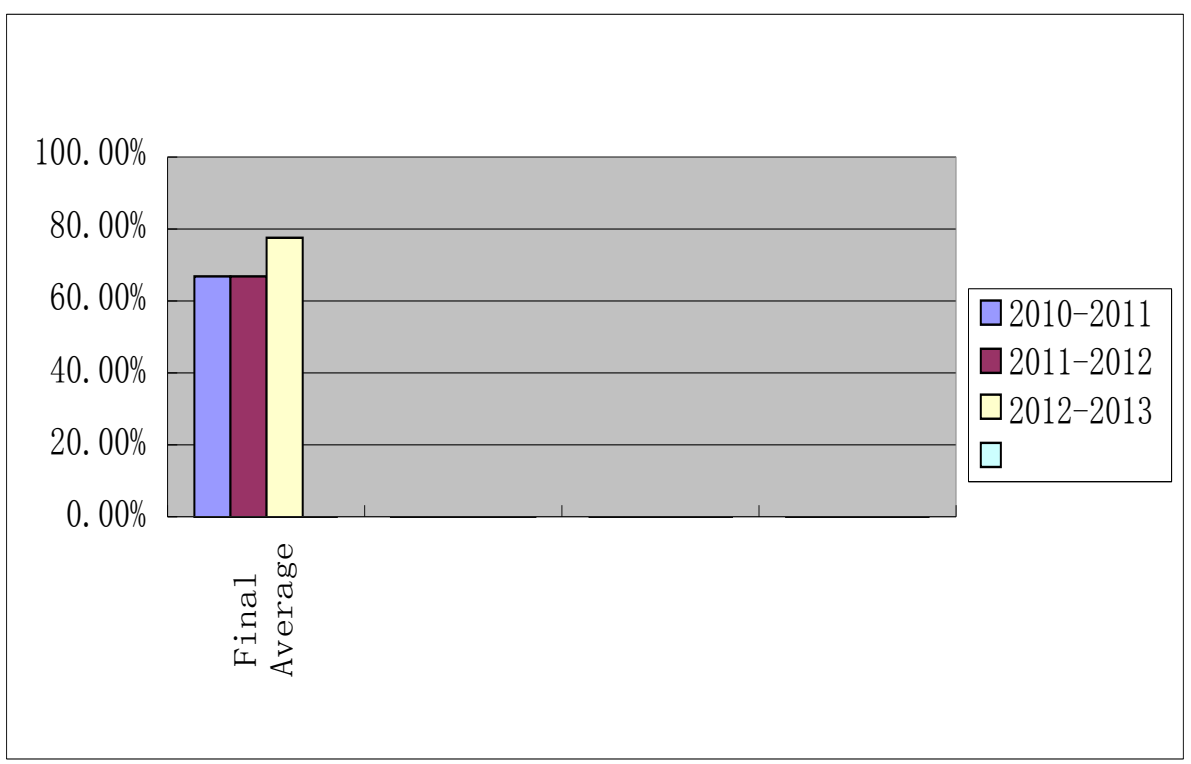




\section{Assessment of Data}

Comparing the results from the collected data in Figure 1 and 2, the student retention rate was increased by $18.5 \%$ for the academic year $2012-$ 2013 than year 2011-2012.The student passing rate remained relatively stable. It has a 6\% decrease from academic year 2010-2011 to 2011-2012, while it has a 4\% increase from year 2011-2012 to year 2012-2013. Comparing the grade distribution of academic year 2011-2012 and year 2012-2013, it shows a 16.6\% increase on A's. It has a small increase in B's and a huge decrease in C's. The newly developed teaching strategy did show great improvement in retaining students and the rate of students obtaining an A average.

(2012-2013) 18 students took the pretest and eight students failed. The passing rate of the pretest was $10 / 18=55.56 \%$. 16 students took the post-test and only one student failed the post-test. The passing rate of posttest was 15/16 $=93.75 \%$. Figure 3 (Final Exam vs. Group Presentation Score) contains a percentage of variance equal to $86.5 \%$, with R-Sq (adj) at 84.3\%. The higher correlation between Final Exam Grade vs. Group Presentation Scores indicates that student group presentation does a positive effect on student final exam grade. In figure 4, the average of final exam had an 10\% increase in year 2012-2013 compared with year 2011-2012.

Data Analysis: The rate of students who obtained A's showed a $16.5 \%$ increase. It showed that student learning improved when working together on presentations. Through group presentations, students understood core concepts and how to apply these concepts to solve real life problems. The final exam average increased $10 \%$. This indicated that group presentation did spur students to review course materials and core concepts.

\section{Conclusion}

The strongest positive outcomes of this project were the quality of student presentations, the increase in student retention rate, and the increase in the number of students who obtained A's in the academic year 2012-2013. Student presentations were counted $10 \%$ of their course grade. During their presentations, students were actively engaged in learning the materials instead of (passively) listening to the lectures. By making quizzes for their classmates, students were inspired to think critically about the course content. By tracking student progress in high level math courses, it showed that it is much easier for students to understand the materials in high level math courses after they fully understood the core concepts in Pre-calculus. Thus it follows that the model of integrating group presentation into teaching and learning core concepts in mathematics should be adapted. 


\section{References:}

Hempel, D., Stenger, T., Orto, M., Stenger, D., Seibel, A., Rohrig, S., ..., Breitkreutz, P. (2014). Analysis of Trainees' Memory after Classroom Presentations of Didactical Ultrasound Courses. Critical Ultrasound Journal, 6 (10). doi:10.1186/2036-7902-6-10.

Alshare, K. \& Hindi, N. (2004). The Importance of Presentation Skills in the Classroom: Students and Instructors Perspectives. Journal of Computing Sciences in Colleges, 19 (4), 6-15.

Fan, L. \& YEO, S. (2007). Integrating Oral Presentation into Mathematics Teaching and Learning: An Exploratory Study with Singapore Secondary Students. The Montana Mathematics Enthusiast, Monograph 3, 81-98.

Chapin, S. H., O'Connor, C., \& Anderson, N. C. (2003). Classroom discussions: Using math talk to help students learn. Sausalito, CA: Math Solutions Publications. 